\begin{abstract}
Unprecedented social and technological developments call into question the meanings and boundaries of privacy in contemporary China. This study examines the discourse of privacy on Sina Weibo, the country's largest social medium, by performing a semantic network analysis of 18,000 postings containing the word “隐私 (privacy).” The cluster analysis identifies eleven distinct yet organically related concept clusters, each representing a unique dimension of meaning of the complex concept. The interpretation of the findings is situated in the discussion of the rapidly evolving private realm in relation to emerging new contexts of the public realm. Privacy, justified for both its instrumental functions and intrinsic values, both reflects and constitutes new forms of sociality on the socio-techno space of Weibo.
\end{abstract}

Keyword: Privacy, Social media, Sina Weibo, semantic network, network analysis 


\section{"Privacy" in Semantic Networks on Chinese Social Media: The Case of Sina Weibo}

Privacy has become one of the most vehemently contested contemporary social issues thanks to revolutionary developments in digital networking and mobile communication technologies. Both popular and scholarly discourses are imbued with uneasiness over ubiquitous public surveillance and information appropriation. However, concerns over privacy are not reducible to relatively simple needs for information control. Technological developments, in fact, have renewed the material conditions that enable emerging practices and shifting notions of privacy.

Conceptions of privacy are rooted in broad social practices at the personal, sociocultural, and political levels (Solove, 2002; Westin, 1967, 2003). More importantly, the normative dimensions of privacy conceptions intersect with basic epistemological and moral concepts such as the nature and forms of human existence, the essence of political reality, and the relative importance of the individual versus the collective (Capurro, 2005; Ess, 2005;). However, mainstream scholarly discourse on privacy tends to privilege liberal individualistic understandings of these fundamental issues since the conventional concept of privacy has evolved within the sociopolitical values of Western democracies. The evocation of the right to privacy represents a commitment to limited government powers in the interest of individual autonomy and liberty at the socio-political level. Grounded on this broad socio-political framework, privacy is a means for the individual to achieve the ultimate end of self-realization in the private realm (Altman, 1975; Margulis, 2003a, 2003b; Rawlins, 1998; Regan, 1995; Westin, 1967, 2003). Consequently, mainstream privacy research tends to be value-driven, making its assessments of and arguments for privacy issues from an individualistic standpoint in the 
modern liberal sense (Kasper, 2005). There are two major caveats to this conceptualization of privacy. First, the focus on the normative dimension of privacy propels researchers to seek the essence of privacy in abstraction, to debate a priori conditions for privacy, and to search for rigid conceptual boundaries at the expense of rich and embedded privacy practices (Solove, 2002). Second, the emphasis on these premises effectively locks the notion of privacy into the particular context of liberal individualism and makes it difficult to understand privacy practices in socio-political environments that did not arise within modern liberal democratic traditions.

This study examines privacy discourses and practices on Sina Weibo, one of the leading social media platforms in China. In this study, Sina Weibo serves as a sociotechno context situated in a Chinese society that is rapidly evolving under pressures from its growing market economy and associated deepening cultural transformations. Weibo also provides the texts that constitute public and private discourses on privacy for this study. By tapping into the rich corpora on Sina Weibo, this study explores the meaning of privacy through related terminological dimensions of particular privacy practices, especially instances of disruption and conflict embedded in Weibo discourses. Instead of moralizing under an overarching essentialist concept of privacy, this study purports to decouple privacy discourses and practices from the prevalent liberal individualist premises, and to understand the issue in relation to China's own social and historical developments.

\section{Changing Private Life in Chinese Society}

Although a desire for privacy appears to be universal, the meaning and the social customs surrounding it differ notably across socio-historical contexts (Gumpert \& 
Drucker, 1998; Moore, 1984; McDougall \& Hansson, 2002). A society’s characterization of privacy says much about both its theoretical and normative understandings of such fundamental issues as the nature of human consciousness and social organization (Cohen, 2001; Ess, 2005).

The problem of privacy is often subsumed within a larger discussion of the relationship of the private realm to the public realm (Gumpert \& Drucker, 1998). However, private life is a historical reality that different societies have construed in different ways (Zarrow, 2002). Cultural and political traditions and realities that delineate private space and conduct serve as the material conditions of privacy. As these conditions come under pressure, the theoretical and normative roots of privacy shift accordingly (Cohen, 2001).

There is not a single Chinese word encompassing all the meanings attached to the English word "privacy.” In English, "privacy" contains several layers of meaning ranging from inner, personal, and family life separate from the public, to individual rights and related concepts (Zarrow, 2002). The indigenous concept of 私 si in Chinese, representing the ideas of the personal and the self, has had to go through a long ideational evolution to shed its negative connotations and acquire legitimacy as a private realm in a collective society. This adaptation of moral values with regard to the private realm in Chinese society reflects the unusual political conditions and increasing tempo of commercialization since the end of the sixteenth century (Zarrow, 2002).

Recent concerns about privacy have arisen in the broad context of contemporary China's rapid transition to a market economy, the growing legitimization of the individual in social practices, and the consequential individualization of Chinese society 
through structural changes of social relations (Yan, 2009). The individual, whose sociopolitical identity had previously always been prescribed by the social collectives he or she was embedded in, has emerged as an independent social category on socio-political grounds. The lives of Chinese individuals have been increasingly oriented toward personal well-being and improvement, shedding age-old moral preference of collective welfare (Yan, 2009). The unprecedented changes in social conditions have created new opportunities for ordinary people to imagine and to practice the idea of the private self (Zarrow, 2002).

It is particularly significant to note the rise of the individual in relation to the family and kinship, the two categories that have long defined the Chinese individual. No longer expected to simply perpetuate the family lineage, the individual in contemporary Chinese society instead pursues her interests through the workings of both the family and "practical kinship". Consequently, the personal network and emotional attachments to kin and friends have become increasingly important in defining individual identity (Yan, 2009).

Similarly, recent decades have also witnessed a reorientation of the thinking about the nature of 公 gong, as in the ideas of the public, the communal, and public space. The rising individuals in Chinese society have been struggling to renew their relationship with new forms of socio-economic institutions, and more importantly, the party-state, which have played a key role in directing the process of individualization. The state-led socioeconomic reforms and polices profoundly affect and effectively manage the interplay among the individual, social institutions, and the market. For this reason, the changing relationship between the individual and the party-state in China does not mean a 
categorical shift toward the same individual-society relationship as in Western Europe (Yan, 2010). If the pursuit of individual interest in China drives an increasing awareness of consumer rights and the development of rights-assertion activities which in turn produce rights-bearing citizens who promote the rule of law in a civil society, the terms through which this is realized must necessarily adapt to or arise within the context of the country's own socio-political history and reality.

Against this backdrop, this study aims to explore the meanings of privacy practices and discourses in contemporary Chinese society. Privacy is a dialectical concept conditioned by people's expectations and experiences as private selves in relation to other social players. It is a dynamic process that undergoes constant negotiation and reorientation as a result of the shifting boundaries between private and public realms in a changing society. Hence, we first ask the following two questions: $R Q_{1}$ : How is privacy discussed and practiced in various private and public realms in Chinese society? And $R Q_{2}$ : What kinds of relationships between the private and public realms do the discourses and practices of privacy reflect or reveal?

\section{Sina Weibo as a Socio-techno Context and Discursive Texts}

The sense of privacy originates in our interactions with and within the social spatial environment (Cohen, 2001; Kisselburgh, 2008). Recent developments of ICTs such as network computing and mobile communication have presented a serious challenge to the physical, psychological, and social mechanisms we draw on for regulating privacy (Kasper, 2005; Solove, 2002). These technologies have reconfigured the media of human communication, the means of information access and storage, as well as the conditions, constraints, and expectations of social interaction. Consequently, the 
structure and logic for organizing understandings of privacy have changed accordingly (Kisselburgh, 2008; Rawlins, 1998).

Moreover, ICTs do not simply provide technical platforms through which we reflect, enact, or debate privacy concerns. Instead, they are a very part of the circumstance within which we formulate and understand these concerns (Palen \& Dourish, 2003). ICTs constitute socio-techno spaces intersecting both physical and virtual worlds, each intersection instantiating a space of potentially conflicting behavioral standards. Our concerns about privacy reveal our constant efforts to manage the boundaries between different realms of action and degrees of disclosure within these socio-techno spaces (Palen \& Dourish, 2003). In such environments, our thoughts and behaviors are understood through both the guidance of existing and emerging social norms and the means of informational representations enabled by the specific media.

The venue of such a socio-techno space for this study is Sina Weibo, one of the largest social media platforms in China. Sina Weibo is a Twitter-like microblogging service provided by the Sina corporation. Launched in August 2009, Sina Weibo quickly became the most popular social media site in the country. It is reported to have over 300 million registered users and generate about 100 million posts per day. The speed and scale at which information spreads on the Sina Weibo network has made it far less subject to control and censorship by the authorities and a preferred platform for information dissemination and social networking. In many ways, Sina Weibo is capable of carrying the conversations of an increasingly vocal public in real time (Magistad, 2012; Qu, Huang, Zhang, \& Zhang, 2011; Yan, 2011). 
Privacy concerns are driven by a combination of technical and social factors. Social media exemplifies the socio-techno space where traditional privacy notions and new privacy practices are contested. For this reason, we ask $R Q_{3}$ : What roles do social media such as Sina Weibo play for online users' privacy practices in contemporary Chinese society?

\section{Methods}

A conventional way to conceptualize privacy is to identify some essential elements common to the private aspects of life and then formulate a concept based on those elements (Solove, 2002). Such conceptualization often results in an abstract category with a priori criteria distinguishing privacy from other things. For instance, privacy has been characterized as limited access, control over personal information, personhood, and intimacy. None of these categories, however, sufficiently reflects the rich meaning of the privacy concept (Kasper, 2005; Solove, 2002).

Instead of trying to summarize and essentialize for an overarching privacy concept, this study takes a pragmatic approach to privacy by identifying and analyzing a set of related dimensions of privacy practices. Solove (2002) argues that any conception of privacy must be responsive to social reality since privacy is, after all, an aspect of concrete social practices contingent on context. Such practices are constituted in the ways in which we employ the word "privacy" in everyday life and the things we refer to when we speak of "privacy."

Privacy in this study is examined as a web of interconnected specific practices or disruptions of such practices embedded in discourses. The task of conceptualizing privacy, therefore, becomes mapping the typography of the discursive network. The 
emerging dimensions of the network are not categories with fixed boundaries but areas where we identify unique patterns in detail. As Solove suggested, "we should act as cartographers, mapping out the terrain of privacy by examining specific problematic situations rather than trying to fit each situation into a rigid predefined category" (Solove, 2002, p. 1126).

For this reason, this study employs semantic network analysis to pursue the meaning of privacy on Sina Weibo. While there have been different methods to conceptualize network ties (traditional content analysis, shared perception, and word association) in existing semantic network analysis research (Doerfel, 1998), this study employs the word association (concept co-occurrence) method which maps the relationship among words by indexing the pairs of concepts. Extending beyond the standard content analysis of texts and frequencies of concepts, such a semantic network analysis reveals the manifest meaning structure of the text and indirectly represents the collective cognitive structure among the creators of the text (Danowski, 1982, 1993) . The semantic network generated in this study identifies major privacy-related concepts in the text data as nodes linked together by the frequencies with which each concept cooccurs with the other concepts. Network clusters that emerge organically from the large network are further identified to illustrate the important dimensions of privacy discourse on Weibo. These clusters are further explained with more detailed examples of the postings following the explication of conventional discourse analysis principles.

The data for this study were gathered in July 2012 by doing a keyword (“隐私 " privacy) search on weibo.com. The resultant 18,000 items were randomly selected among all the postings generated by Sina Weibo users from March to June, 2012. Prior to 
analysis, we scrubbed the raw corpus of irrelevant information such as user ID and textual “noise” such as stray punctuation, symbols and affirmative utterances (啊, 嗯, 哦, etc). For word tokenization, we used ICTCLAS (http://ictclas.org/, ICTCLAS, 2012) to select all the nouns, verbs, and adjectives from the cleaned corpus. ICTCLAS is one of the most reliable and effective textual tokenization tools for the Chinese language with an accuracy rate up to $98.45 \%$ (ICTCLAS, 2012).

In the first step, we performed both a conceptual and a relational analysis on the text in order to identify privacy-related concepts and measure the frequencies of the cooccurrences of these concepts. The analyses were conducted using WORDij 3.0 (Danowski, 1993, 2010), a computer program that combines multiple analytic techniques including content analysis, computational linguistics, and network visualization. Wordij 3.0 has been used in many research projects published in leading journals to perform text mining (e.g. Peng et al., 2012) and semantic network analysis (e.g. Danowski \& Cepela, 2010; Smith \& Parrott, 2012). We used WORDij’s WordLink program to identify concepts that co-occur with the word "privacy (隐私)" more than ten times in the corpus. Co-occurrence of a word pair is defined as the two terms appearing together within a three-word window (see Danowski, 1993; Zywica \& Danowski, 2008). A semantic network then was generated by linking these words based on the frequencies of their cooccurrences. Altogether 385 nodes (words/terms/concepts) comprise the resultant network.

Next, we loaded the network data, consisting of a list of concept node pairs and their aggregated frequencies, into NodeXL (https://nodexl.codeplex.com/ Smith, et al, 2010), an online network analysis tool. A cluster analysis was performed in NodeXL 
using the Clauset-Newman-Moore algorithm (Clauset, Newman, \& Moore, 2004). A cluster is a densely connected subset of nodes more related to one another than to other nodes in the network. A semantic cluster may reflect a unique dimension of meaning embedded in the concept of privacy. To get an optimal result, we excluded the dominant keyword “privacy” (隐私) from the cluster analysis and visualization.

Finally, we used Gephi (https://gephi.org/) to visualize the full network and the clusters. The sizes of the nodes are proportionate to the percentages of the nodes linked to them. The distance between words on the cluster graphs reflects strength of relationship between these concepts, i.e. the frequency with which the word pair is linked. Concepts with stronger relationships appear closer together, and concepts with weaker relationships are further apart.

\section{Results}

Figure 1 displays the full semantic network from the original corpus in Chinese characters. Working with Chinese characters was one of the biggest challenges to this project. A meaningful interpretation of the findings depends on the successful tokenization of the Chinese corpus and network construction. Therefore, we kept Chinese characters in our presentation of the concepts and terms whenever possible. Altogether, eleven clusters emerge from the cluster analysis.

Among these groups, Group 1 has the largest number of words (see Figure 2). The overwhelming majority of the words in Group 1 describe various social roles such as Mom (妈妈), wife (老婆), superiors (上司), and social relationships such as friends (朋 友) and colleagues (同事). The rest include organically related concepts that describe social settings (family 家庭, marriage 婚姻), awareness, emotions, and actions with 
regard to privacy (respect 尊重, lose 失去, disgusting 讨厌, villains 小人), as well as associated themes and subject content (hopes 希望, happiness 快乐, growing up 成长). This group essentially depicts a personal realm for the notion of privacy.

Insert Figure $1 \& 2$ about here.

Group 2, the second largest network, is distinct with words from the media and technological realm (see Figure 3). The nodes such as user (用户), information (信息), software (软件), cell phone (手机), network (网络), and download (下载) carry with them the informational dimension of the privacy concept. Obviously, privacy concerns are accentuated by the ease of information dissemination enabled by digital media technologies. There is also a journalism-media aspect of the concept represented in such words as the media (媒体), news (新闻), report (报道), and reporters (记者).

Insert Figure 3 about here.

Words making up Group 3 and Group 4 seem to describe socio-professional environments of the privacy concept (see Figure 4). We can see such words as student ( 学生) and teacher (老师) paired with words such as classroom (教室) and dormitory (宿 舍). Boss (老板) and customers (客户) appear with office (办公室). Civil servants (公务 员) and officials (官员) are close to government (政府). Venereal disease (性病) is linked with hospitals (医院). We also noticed that privacy is being discussed in terms of public policy, as evident in such words as the police (警察) and society (社会), as well as standards (标准), regulations (规定), rules (法则), and laws (法律). The thematic words of this socio-professional sphere seem to be infringement (侵犯), survival (生存), safety ( 安全) and dignity (尊严). 
Insert Figure 4 about here.

Group 5 sheds light on a specific instance of privacy concerns, namely, the ease of shooting (拍照, 拍摄), displaying (展示), forwarding (转发), and deleting (删除)

photos (照片) and records (记录) (see Figure 5). In addition, words in the cluster such as strangers (陌生人), familiar (熟悉), and city (城市) depict the larger context of technological concerns. This network, therefore, spans both the social and technological realms.

Insert Figure 5 about here.

Group 6 and 7 are topic areas concerned with public policies. While the former includes the police (警察), police stations (警察局), fines (罚款), and detention (拘留), the latter touches on larger political concepts such as the state (国家), human rights (人权 ), the people (人民), and top secrets (机密). These two clusters represent the public and political spheres in which privacy is experienced and understood (see Figure 6).

Insert Figure 6 about here.

The rest of the groups are much smaller in size and more homogeneous in node composition. Group 8 seems to concern family affairs (家事) and related emotions (fear 害怕) and norms (considerate 体贴) (see Figure 7). Group 9 is apparently derived from public responses on Sina Weibo to the story of one or more fame-hungry (出名), scandalous (丑闻), entertainment program (节目) actress(es) (女星) (see also Figure 7). Group 10, with only three nodes (the room 房间, glass 玻璃, intimacy 亲密), is best characterized as socio-spatial. Finally, the two nodes in Group 11 (angry 生气 and sad 伤 心) denote the socio-emotional dimension. 
Insert Figure 7 about here.

These mutually distinct yet organically related semantic network clusters effectively identify several important dimensions of meaning with regard to the concept of privacy as reflected in Sina Weibo postings. These dimensions delineate the diverse social contexts wherein the private self interacts with other key aspects of contemporary Chinese society. Privacy concerns are most immediate and thus most palpable where the individual conducts her daily life in close company with her family and friends. Similar tensions naturally extend to professional environments as professional relations often entangle with personal relations in the Chinese context. And finally, there are political discourses fermenting via the trope of privacy on Sina Weibo. Such political discourses reflect how Chinese individuals envision their relationship with the party-state. Together these dimensions are constitutive of an organic lifeworld embodying a logic of understanding that does not fit Western normative individualist frameworks and conceptions. Rather these discourses and practices provide concrete contexts and bases from which to evaluate the purposes privacy serves and construct its normative ends in light of Chinese society's own traditions and realties. Moreover, the cluster analysis characterizes Sina Weibo as a socio-techno space where the media and technology reformulate and accentuate the concerns and conflicts of the lifeworld.

\section{Discussion}

The liberal individualistic perspective prescribes privacy as a means for the individual to achieve the ultimate end of self-identity and self-realization. Social relationships, on the other hand, are deemed either voluntary or barriers to individual independence (Altman, 1975; Margulis, 2003a; Rawlins, 1998; Westin, 1967). In the Sina 
Weibo corpus, the word that co-occurs most frequently with “privacy (隐私)” is “the individual (个人).” Respect for individual privacy or the lack of individual privacy are the two most common themes on Sina Weibo. Indeed, "privacy" seems to indicate an acute sense of individuality. However, this new sense of individuality still engages in constant dialogue with the traditional Chinese self embedded in a network of relations and situations. As evident on Weibo, the notion of “individual privacy (个人隐私)" frequently arises in personal relationships, as in the following example:

@ Please respect our individual privacy, if you dare to eavesdrop on my phone conversations again, I'll never tell you who called and what it's about again...

In fact, the word privacy takes on diverse and particular meanings when it is talked about in relation to parents, siblings, friends, significant others, colleagues, and schoolmates. In the following posting, for instance, privacy is understood as secrets keeping one from getting close to her romantic partner.

@ You don't let me touch your cell phone saying that I need to respect your privacy. I don't understand: if you don't have anything to hide from me why can't I take a look at it? You can inspect my phone however you want because I love you so much that everything I have is open to you. The fact that you keep me away from your phone only makes me feel that you are keeping secrets from me...

In a sense, the concept of privacy provides an opportunity for people to think about their personal relationships and make sense of the evolving social norms that regulate these relationships:

@ A personal space is needed even when with the best friend. Privacy not only won't estrange feelings but also allow us to establish the sense of safety and trust. 
@ Violate your privacy, meddle with your friends,... make you so tired, I feel sorry about it. But don't you think love is selfish? ...Don't you think we need to sacrifice for love, don't make me feel that your schoolmates and friends are more important than me! I do care!

Moreover, concerns about privacy are often discussed in relation to social roles and the obligations prescribed to those roles. For instance, a mother's responsibility trumps one's sense of privacy over her body, an idea forcefully expressed in the following posting:

@ The so-called privacy of a female's body is non-sense: when feeding a baby, a woman's breast is not just for display but a practical tool!

Lastly, privacy is very much a gendered topic on Sina Weibo. The following is one of many different versions of a typical friendly reminder to women who are susceptible to the pitfalls of unwise relational moves, of which privacy is one:

@It's silly for a woman to...1..., 2. ..., 3. ..., 4. pry on a man's privacy like a spy.

But apparently men are equally subject to judgment when it comes to privacy: @ So fragile as to reply on the privacy settings to shut off comments, are you still a man?

These examples demonstrate that, rather than serving the purpose of one's selfcontained, controlled, and chosen identity, ideas of privacy on Sina Weibo are often expressed in contexts that are relational, role-oriented, and gendered. Privacy on Sina Weibo draws upon as many obligations as rights, as much emotion as information, as much role-defining and relationship-maintenance as interpersonal border control. In a 
sense, the notion of privacy provides a conceptual vehicle for people to contemplate relational norms.

@ If a guy would: 1. Tell you his QQ [a popular Chinese IM platform] password. 2. Tell you his bank card password...4. Allow you to check his cell phone anytime... Then, marry him!

@ Many people show their understanding and sympathy for you only to pry on your privacy. This common sense should be remembered all the time to protect yourself.

As a contested conceptual vehicle, the notion of privacy also often appears side by side with both new liberal ideas and traditional understandings. The following is a posting in immediate response to the above marriage call:

@ Everyone needs freedom, privacy, character and temperament. Point 1, 2, 4... are rather perverse...

The notion of privacy is also rich enough to characterize the general social atmosphere. The following laments the loss of strong emotional interpersonal attachments to the ills of urbanity:

@ This city is big enough to tolerate all your eccentricities and habits. People are busy with their own lives, taking indifference as a respect of privacy. People always say it's fine nothing serious alright $O K$, So do you. People come to you to confide their grievances, and leave you to go on with their lives afterwards, you don't care much about it either because you only pretend to listen. The world is so big but we are so lonely!

As China is well on its way to become a more open, modern, and highly mobile society, there have been rising concerns about how the long tradition of personal trust adapts to increasing interaction among unrelated individuals. The semantic analysis 
results seem to show that beyond entangled webs of personal relationships, privacy still belongs to more general and abstract “others” (别人, 他人, 对方, 人家). Between understandings of privacy in the contexts of particular personal relationships and a general sense of privacy for all, Sina Weibo users relate a wide range of different actions to privacy, most with negative connotations: see (看), spread (传播), touch on (触及), discuss (议论), leak (泄露), disclose (透露), share (分享), gossip (八卦), infringe (触犯), invade (侵犯), dig (挖), pry (窥探), expose (揭露, 暴露), publicize (宣扬), lose (弄丢). Some are positive: care (注重), respect (尊重), preserve (保留), protect (保护), guarantee (保障); the rest are neutral such as self-express (晒), or new such as forward (转载) (a novel ICT-enabled action). These actions are an impressive display of not only the broad set of connotations the concept of privacy entails but also the nuanced understandings of privacy embedded in an expanded scope of social relationships

Existing scholarship on privacy in the Chinese context tends to argue for the rationale of privacy protection as an instrumental good instead of an intrinsic value (Lü, 2005). Evidence from Sina Weibo shows that privacy is deemed it both an intrinsic imperative and an instrumental necessity. One the one hand, it is related to such fundamental moral values as dignity and respect. On the other, it is also part of the material condition for safety:

@ An important criterion to judge if one is a person of virtue or vice is to see if she is interested in other peoples' privacy...

@Three kinds of wealth in one's life: 1. health, 2. privacy, 3. freedom.

@It's common on Weibo that proud parents use their children's pictures as their profile pictures, mention their children's names, and the names of their kindergartens 
and schools, expose their neighborhoods in pictures...Hope parents realize these are all children's important privacy, think twice before you post on Weibo.

Privacy is deemed a human right in liberal individualistic frameworks, which are premised on the primacy of the private individual and its separation from, or even opposition to, the state and other forms of social power. Emphasizing the choice and control of the autonomous individual, this perspective sees important threats to privacy arising from organization-individual relationships (Margulis, 2003b; Regan, 1995; Westin, 2003).

As new types of social interaction, such as that of citizen-government, employeeemployer, and consumer-business, become increasingly important for social integration in contemporary Chinese society, social relations in the contexts of various social institutions have become ever more complex. The dynamics of social interaction and emerging norms are often reflected in privacy concerns:

@Marriage and family are beyond the authority of an employer. An employer's interference is an immoral and illegal infringement of employees' privacy.

@ XX hospital ignores patients' right to privacy by leaving patients' medical records open for unauthorized access by anyone...

A modern sense of distinction between the private (私) and the public (公) seems to arise when people pay more attention to the boundaries between impersonal professional environments and the personal realm. Nevertheless, such a distinction is still nebulous and subject to discussion, as exemplified in the following much reposted posting: 
[Ten pieces of wisdom at the workplace] @1.Don't be antisocial, have harmonious interpersonal relations. 2. Don't confide to colleagues. 3. Don't handle personal things during business hours. 4. Don't gossip about colleagues ... 5. Don't reveal privacy at will....

Moreover, there is ample evidence on Weibo that people have started to talk about privacy as a kind of right (隐私权). However, the use of the word "rights" does not necessarily indicate a pure legal political notion. The reference to rights is often a form of emphasis when it is applied to networks of relations for Chinese social media users.

@ Do I have the right to privacy or not! I can't eviscerate myself to show you everything even in the name of the greatest love!

In addition, the right to privacy is often understood and grounded on particular personal experience, for instance, as a consumer in the market, and the belief that the government has the responsibility to make public policies protecting this right.

@ Car insurance is expiring. Have been bombarded by text messages and phone calls from many insurance companies for almost a month. I don't check such texts or answer such calls anymore. There have been numerous public discussions about personal information being profited from and appropriated. When will the government issue laws to protect citizens' basic right to privacy. My request is not too demanding, living on this land, I need to feel a sense of safety.

Nevertheless, liberal democratic ideas are still an important part of the political discourse on privacy coming from an increasingly individualized, urban, young, and relatively better educated "middle social stratum" (CNNIC, 2010; Huang 2008) that populates Chinese social media. This middle stratum shows much enthusiasm in 
following these democratic ideas to re-imagine and reorganize political life for the public good.

@....In the U.S., it is ok to keep a secret of one's property but that of government officials must be open to public scrutiny; In the U.S., the right to privacy is guaranteed for everyone but government officials.

@ Comment No. 2 on <the pending regulation that requires real name for user registration on online forums and Weibo>: I support real name registration for the purpose of cracking down on online rumors and crimes, but the premises for that are 1 , the ability of websites to protect users' privacy 2, if the government can tolerate reasonable criticisms 3, if online criticisms and disclosures are protected from retribution. Under the current circumstances, these premises are nonexistent.

Finally, social media as such Sina Weibo provide a new socio-techno space where extended debates and discussions of privacy happen. This space is understood and accepted as a socio-techno artifact that takes place simultaneously with other new things that have brought about changes in life:

@...mortgages take away the future, marriages take away passion, the market takes away the bottom line, Weibo takes away privacy.

It is an open technological platform turned into a private personal space by some: @I don't' have any schoolmates on Weibo, all my grievances are to myself, therefore I have my privacy.

@ I'm lucky that no one from my family knows my Weibo ID. ... It would be really awkward if they snoop on my privacy. Really awkward. 
These two examples seem to instantiate the notion of "public privacy," which occurs when the individual expresses herself openly in an anonymous environment, in this case, an anonymous virtue environment (Westin, 1967, pp. 31-32). However, there may be different understandings of the character of such an environment. While some mean to make public aspects of their private lives, others deem such a virtue environment an extension of the private realm.

Apparently new ICTs have led to the steady decline of clearly situated actions and understandings (Palen \& Dourish, 2003). The nature and function of Weibo as a sociotechno space becomes implicated in the debates over what constitutes "private" and what "public" means at a time when the two axes of the lifeworld are undergoing radical transformation.

@ Weibo is the easiest way to pry on privacy.

@ ...things that are made public on Weibo cannot be called privacy, can only be called personal things...

Capurro (2005, p. 40) argues that when "our being-in-the-world-with-others is basically a being-in-the-networked-world," the very nature of autonomy and individuality seems to evolve into, paradoxically, a networked individuality. Such confusions voiced on Sina Weibo seem to reflect the complexity the Chinese individuals face in response to both the cultural self as a network of relations and new technologically-enabled networks of connections.

\section{Conclusion}

Contemporary China is in a period of rapid social transformation. An expanding market economy, the growing importance of new forms of sociality, an emerging sense 
of individuality, along with the fast development of ICTs are all part of the contemporary environment that is cultivating and reframing people's understandings of privacy. The discourse on privacy on Chinese social media not only reflects but also constitutes changes in people's lifeworlds.

Demographically distinct from the broader population, typical Chinese Internet users - urban, young, and relatively better educated - have experienced improved social and spatial mobility that has pushed them to the forefront of the individualization process in Chinese society (Yan, 2009). At the same time, trends in the market economy provide contexts for imagining and practicing new types of social relations, such as citizengovernment and consumer-business relationships.

The notion of privacy has penetrated deeply into the personal realm in Chinese social media. On the one hand, privacy has been integrated into practices and norms of social roles and personal relationships. The choice between disclosure and privacy reveals expectations and strengthens or weakens trust in personal relationships. On the other hand, the notion of privacy brings about ideas and practices that stir changes in the personal realm. Spouses and friends have to struggle with the heightened sense of individual independence embedded in the concept, as much as women and men have to face new behavioral stereotypes in the name of privacy. The role-oriented and gendered discourse on privacy reflects the intensified conflicts between rights and obligations, disclosure and distance, dependence and independence in the personal and other closely linked socio-cultural realms. Moreover, Privacy is understood on Sina Weibo for both its intrinsic values and instrumental purposes. The dignity of the self and the safety of the family are the two forces driving the increasing consciousness of the privacy concept. 
More importantly, the sense of the self is experienced in new forms of sociality in emerging new contexts of social and public realms while concerns for privacy embody patterns of social interaction in these new contexts. People express in privacy concerns their experiences with others in professional settings and in the contemporary sociospatial environment of heightened mobility. Privacy is embraced as a form of legal rights for consumers in the market. Privacy consciousness also applies to the political arena, both reflecting and affecting power relationships among the government, officials, and ordinary citizens.

Whereas the individual's gain often means the society's loss in liberal individualistic societies (e.g. Gumpert \& Drucker, 2001), privacy in the Chinese context involves a parallel process of reorienting personal relations and activating the public realm for social integration in a modern sense. In other words, the personal is redefined in relation to new public contexts, such as professional life, the political arena, and the impersonal market. This reminds us that privacy and publicness are mutually implicated notions that are historically and contextually defined (Rawlins, 1998).

Discussion of privacy on Sina Weibo reveals growing sensitivity to state surveillance and the intrusion of commercial interests. We see emerging public discourse organized around a free-standing right-to-informational privacy theme (Westin, 2003).

The notion of privacy is also seen to be connected with the exercise of responsible citizenship. Yet discussion of privacy in the individual-state relationship needs to be situated in the long Chinese political tradition in which the state is bestowed with both moral and absolute authority while the individual relies on the state for protection and well-being (Yan, 2009). 
Privacy is thus a sweeping term encompassing everything from the quest for personal dignity and safety to the growing sense of political participation in contemporary China. It carries with it fresh perspectives for understanding the relationship between self and others, individual and collectives, private and public, as well as spatial boundaries in broader contemporary Chinese society.

Moreover, the concept of privacy serves as an interpretive device for exploring the sociopolitical implications of the socio-techno spaces enabled by social media such as Sina Weibo (Rawlins, 1998). Situated in this changing social environment, the sociotechno space of Sina Weibo is not simply a passive conduit for preexisting social values. It provides contexts that affect not only the amount of privacy we enjoy, but also the very ways we think about privacy. It offers a venue for privacy to be displayed, practiced, and contested. Indeed, privacy concerns in contemporary society are largely attributable to the conflict between the changing communicative environment and the traditional constructions of privacy that predate current technological developments.

Privacy has a normative component that relates to our understanding of fundamental human nature and political reality (Kasper, 2005; Solove, 2002). In this sense, privacy is not just found but constructed based on how we envision individuality with its practical implication as autonomous participants in modern society and how we understand our dependency on larger social collectives that sustain a certain desirable social order (Ess, 2005; Reiman, 1976). Such normative construction requires we examine privacy as aspects of social practices, its role in particular practices, and the ends that these practices further, all within the specific context of the social-historical development of the given society. 


\section{References}

Altman, I. (1975). The environment and social behavior: Privacy, personal space, territory and crowding. Monterey, CA: Brooks/Cole Pub. Co., Inc.

Altman, I. (1977). Privacy regulation: Culturally universal or culturally specific? Journal of Social Issues, 33(3), 66-84. DOI: 10.1111/j.1540-4560.1977.tb01883.x

Capurro, R. (2005). Privacy. An intercultural perspective. Ethics and Information Technology, 7(1), 37-47.

China Internet Network Information Center (CNNIC). (2010). Statistical survey report on the Internet development in China. Beijing: Author.

Cohen, J. E. (2001). Privacy, ideology, and technology: A response to Jeffrey Rosen. The Georgetown Law Journal, 89(6), 2029.

Clauset, A., Newman, M., \& Moore, C. (2004). Finding community structure in very large networks. Physical Review E, 70(6), 066111. DOI:

10.1103/PhysRevE.70.066111

Danowski, J. A. (1982). Computer-mediated communication: A network-based content analysis using a CBBS conference. Communication yearbook, 6, 905-924.

Danowski, J. A. (1993). Network analysis of message content. G. Barnett, \& W. Richards (eds.). Progress in communication sciences XII (pp. 197-222). Norwood, NJ: Ablex.

Danowski, J. A. (2010). WORDij 3.0 [computer program]. Chicago: University of Illinois at Chicago.

Danowski, J. A., \& Cepela, N. (2010). Automatic mapping of social networks of actors from text corpora: Time series analysis. Data Mining for Social Network Data, 31- 
46.

De Boni, M., \& Prigmore, M. (2004). A Hegelian basis for privacy as an economic right. Contemporary Political Theory, 3(2), 168-187.

Doerfel, M.L. (1998). What constitutes semantic network analysis? A comparison of research and methodologies. Connections, 21, 16-26.

Ess, C. (2005). “'Lost in translation'”?: Intercultural dialogues on privacy and information ethics (introduction to special issue on privacy and data privacy protection in asia). Ethics and Information Technology, 7(1), 1-6.

Gumpert, G., \& Drucker, S.J. (1998). The demise of privacy in a private world: From front porches to chat rooms. Communication Theory, 8(4), 408-425. DOI: 10.1111/j.1468-2885.1998.tb00227.x

Gumpert, G., \& Drucker, S.J. (2001). Public boundaries: Privacy and surveillance in a technological world. Communication Quarterly, 49, 115-129.

DOI:10.1080/01463370109385620

Huang, P. C. (2010). China's hidden agricultural revolution. (In Chinese). Beijing: Law Press.

ICTCLAS. (2012). About ICTCLAS. Retrieved August 22, 2012, from $\underline{\text { http://ictclas.org/ictclas_about.html }}$

Kasper, D. V. S. (2005). The evolution (or devolution) of privacy. Sociological Forum, 20, 69-92. DOI: DOI: 10.1007/s1 1206-005-1898-z

Kisselburgh, L. G. (2008). The social structure and discursive construction of privacy in sociotechnological realms. (Unpublished doctoral dissertation). Purdue University, West Lafayette, IN. 
Lü, Y. (2005). Privacy and data privacy issues in contemporary China. Ethics and Information Technology, 7, 7-15. DOI: DOI 10.1007/s10676-005-0456-y

Magistad, M. K. (2012). How Weibo is changing China. Retrieved August 22, 2012, from http://www.yaleglobal.yale.edu/content/how-weibo-changing-china

Margulis, S. (1977). Conceptions of privacy - current status and next steps. Journal of Social Issues, 33(3), 5-21. DOI: DOI: 10.1111/j.1540-4560.1977.tb01879.x

Margulis, S. (2003a). Privacy as a social issue and behavioral concept. Journal of Social Issues, 59, 243-261. DOI: DOI: 10.1111/1540-4560.00063

Margulis, S. (2003b). On the status and contribution of Westin's and Altman's theories of privacy. Journal of Social Issues, 59(2), 411-429. DOI: 10.1111/1540-4560.00071

McDougall, B. S., \& Hansson, A. (2002). Chinese concepts of privacy. Leiden: Brill. Moore, B. (1984). Privacy: Studies in social and cultural history. New York: M.E. Sharpe.

Palen, L., \& Dourish, P. (2003). Unpacking "privacy" for a networked world. SIGCHI Conference on Human Factors in Computing Systems, 129.

Peng, T. Q., Zhang, L., Zhong, Z. J., \& Zhu, J. J. (2012). Mapping the landscape of Internet studies: Text mining of social science journal articles 2000-2009. New Media \& Society.

Qu, Y., Huang, C., Zhang, P., \& Zhang, J. (2011). Microblogging after a major disaster in China: A case study of the 2010 Yushu earthquake. 2011 ACM Conference on Computer Supported Cooperative Work, 25.

Rachels, J. (1975). Why privacy is important. Philosophy \& Public Affairs, 323-333. 
Rawlins, W. K. (1998). Theorizing public and private domains and practices of communication: Introductory concerns. Communication Theory, 8(4), 369-380. DOI: DOI: $10.1111 / \mathrm{j} .1468-2885.1998 . t b 00225 . x$

Regan, P. M. (1995). Legislating privacy: Technology, social values, and public policy. Chapel Hill: University of North Carolina Press.

Reiman, J. (1976). Privacy, intimacy, and personhood. Philosophy \& Public Affairs, 6, 26-44.

Smith, M., Milic-Frayling, N., Shneiderman, B., Mendes Rodrigues, E., Leskovec, J. \& Dunne, C. (2010). NodeXL: A free and open network overview, discovery and exploration add-in for Excel 2007/2010. Retrieved 09/05, 2012, from http://nodexl.codeplex.com/

Smith, R. A., \& Parrott, R. L. (2012). Mental representations of HPV in Appalachia: Gender, semantic network analysis, and knowledge gaps. Journal of Health Psychology, 17(6), 917-928.

Solove, D. J. (2002). Conceptualizing privacy. California Law Review, 90(4), 10881154.

Taylor, H. (2012). Most people are "privacy pragmatists" who, while concerned about privacy, will sometimes trade it off for other benefits. Retrieved August 22, 2012, from http://www.harrisinteractive.com/harris_poll/index.asp?PID=365

Westin, A.F. (1967). Privacy and Freedom. New York: Atheneum,.

Westin, A. F. (2003). Social and political dimensions of privacy. Journal of Social Issues, $59,431-453$.

Yan, Y. (2009). The individualization of Chinese society. Oxford: Berg. 
Yan, Y. (2010). The Chinese path to individualization. The British journal of sociology, 61(3), 489-512.

Yan, Y. (2011). Dingxin Zhao: Weibo has changed China. Time Weekly 155. Retrieved from: http://time-weekly.com/story/2011-11-17/120430.html

Zarrow, P. (2002). The origins of modern Chinese concepts of privacy: notes on social structure and moral discourse, in McDougall, B. and Hanson, A. (eds), Chinese concepts of privacy (pp. 121-146). Leiden and Boston: Brill.

Zywica, J., \& Danowski, J. (2008). The Faces of Facebookers: Investigating Social Enhancement and Social Compensation Hypotheses; Predicting Facebook ${ }^{\mathrm{TM}}$ and Offline Popularity from Sociability and Self- Esteem, and Mapping the Meanings of Popularity with Semantic Networks. Journal of Computer-Mediated Communication, 14(1), 1-34. 
Figure 1

The Semantic Network of Privacy on Sina Weibo

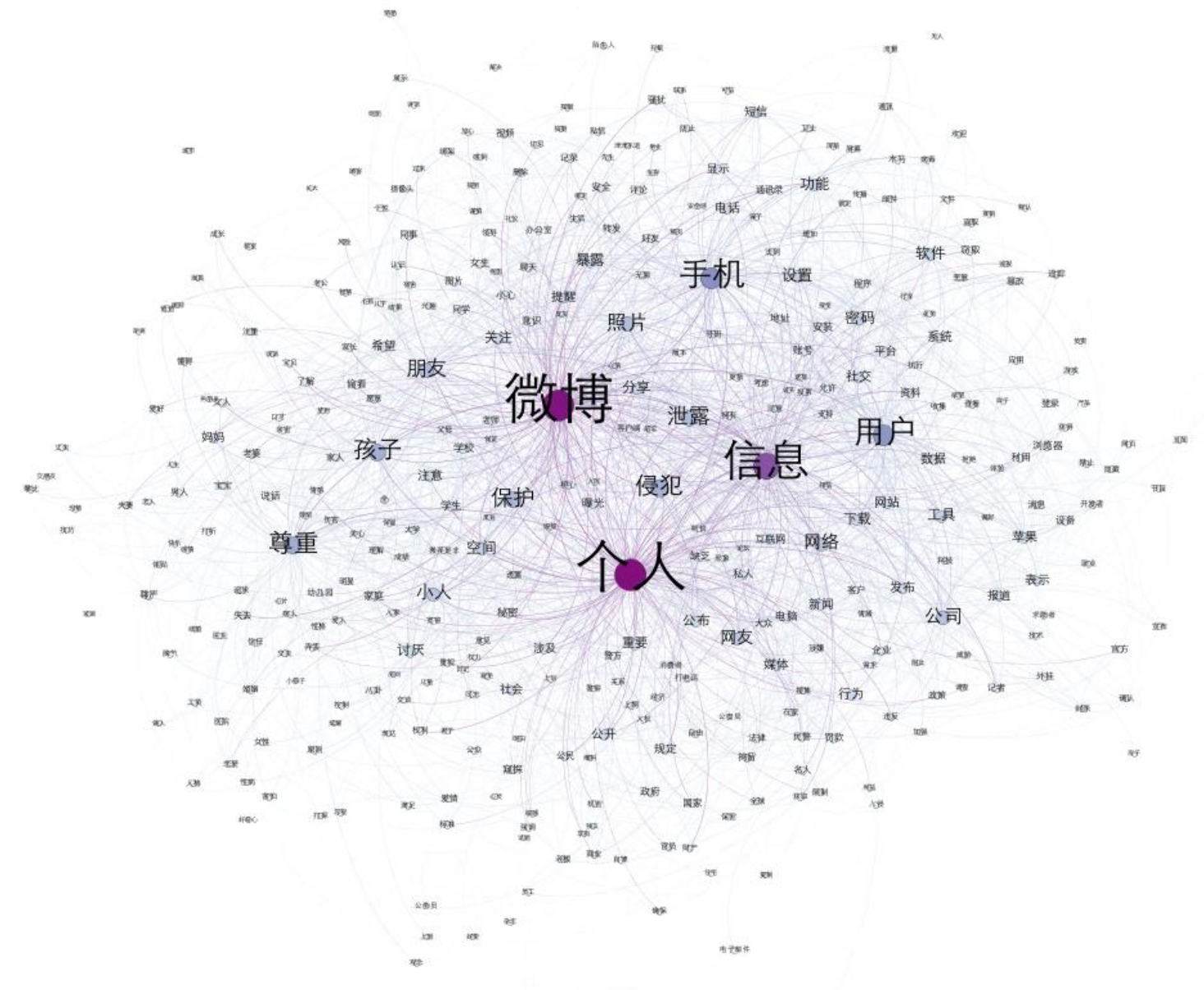


PRIVACY IN SEMANTIC NETWORKS ON LINA WEIBO

32

Figure 2

Group 1 the Personal Sphere of Privacy on Sing Weibo

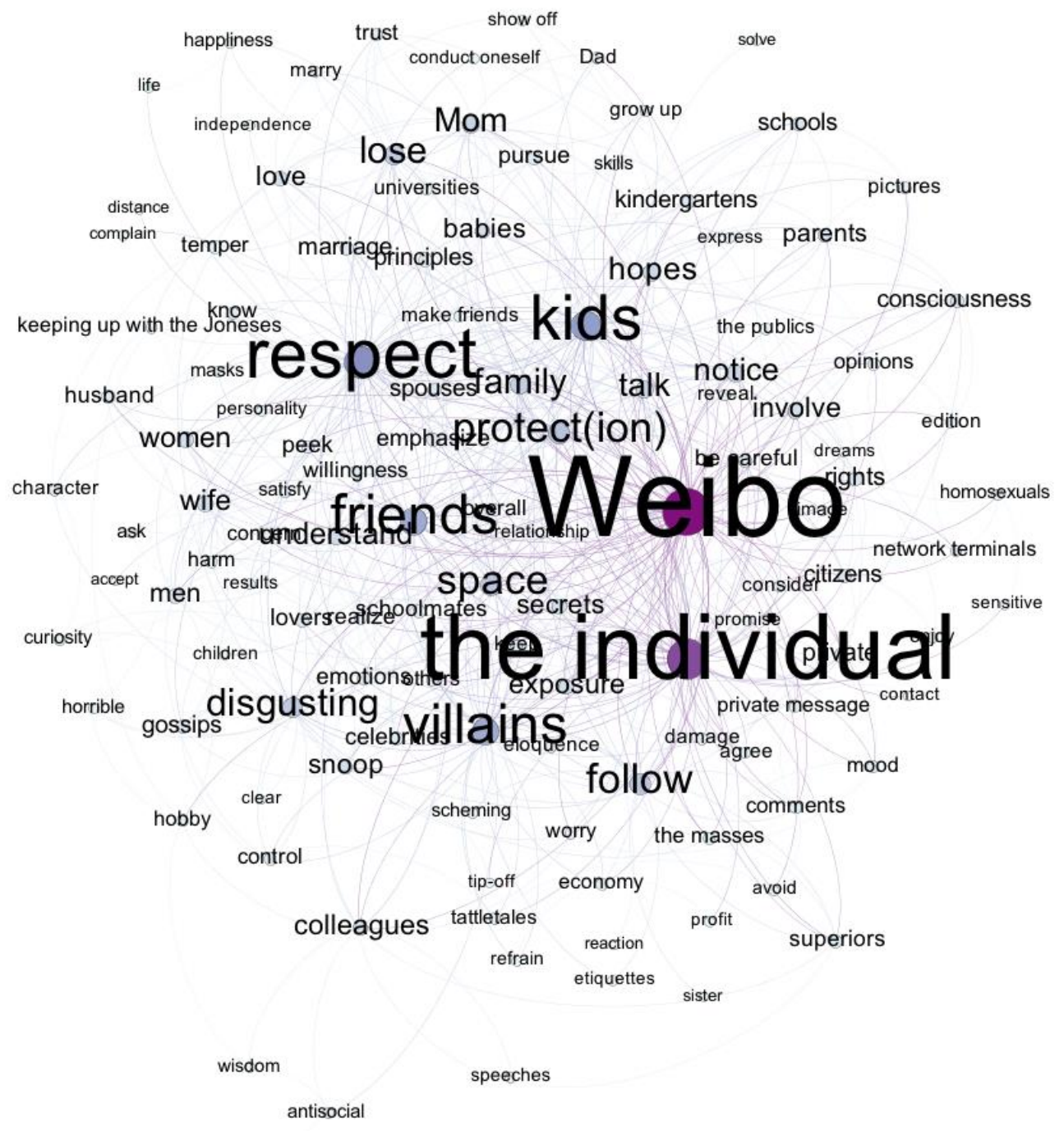

behave 
Figure 3

Group 2 the Technological and Media Sphere of Privacy on Sina Weibo

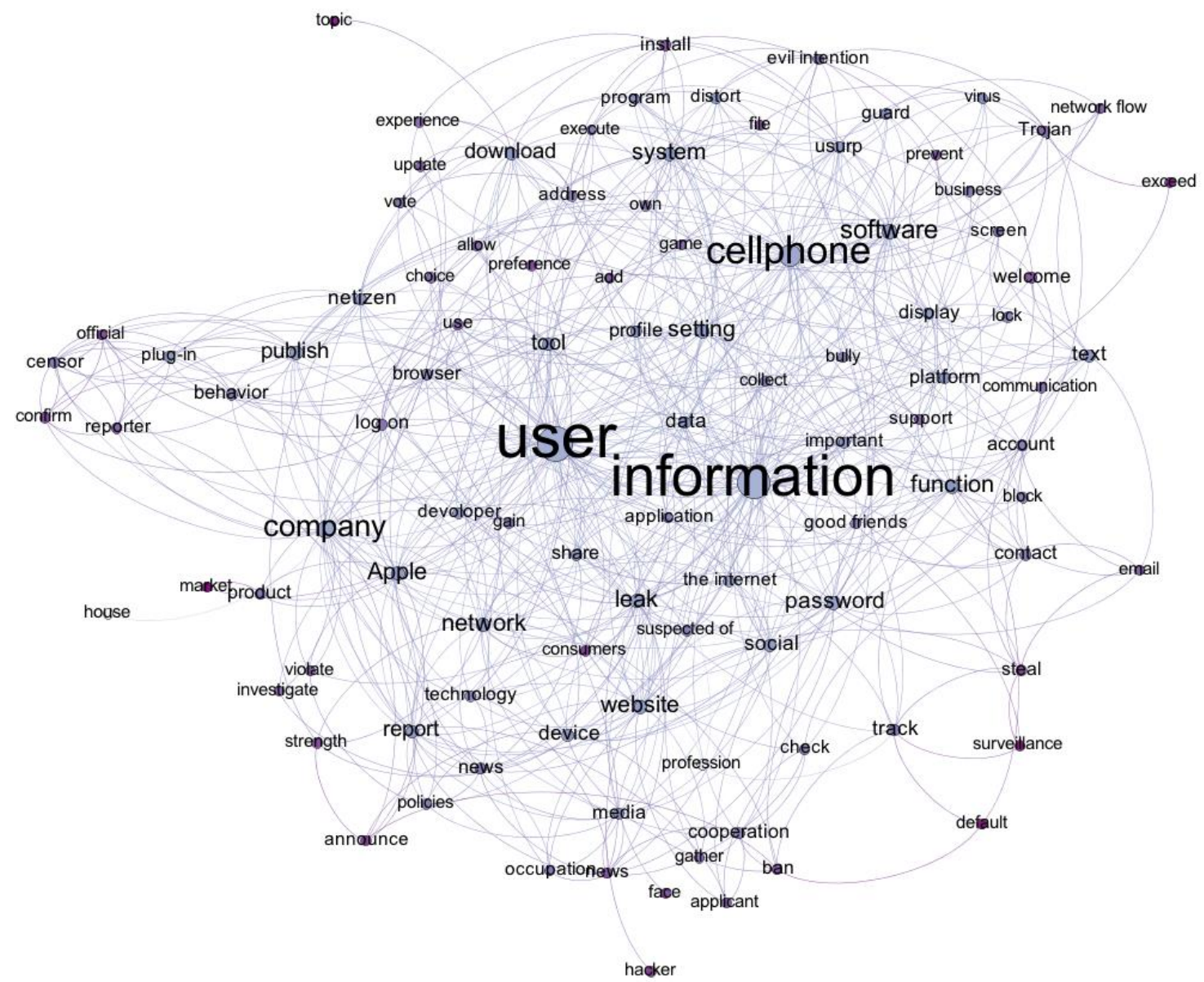


Figure 4

Group $3 \& 4$ the Socio-Professional Sphere of Privacy on Sina Weibo
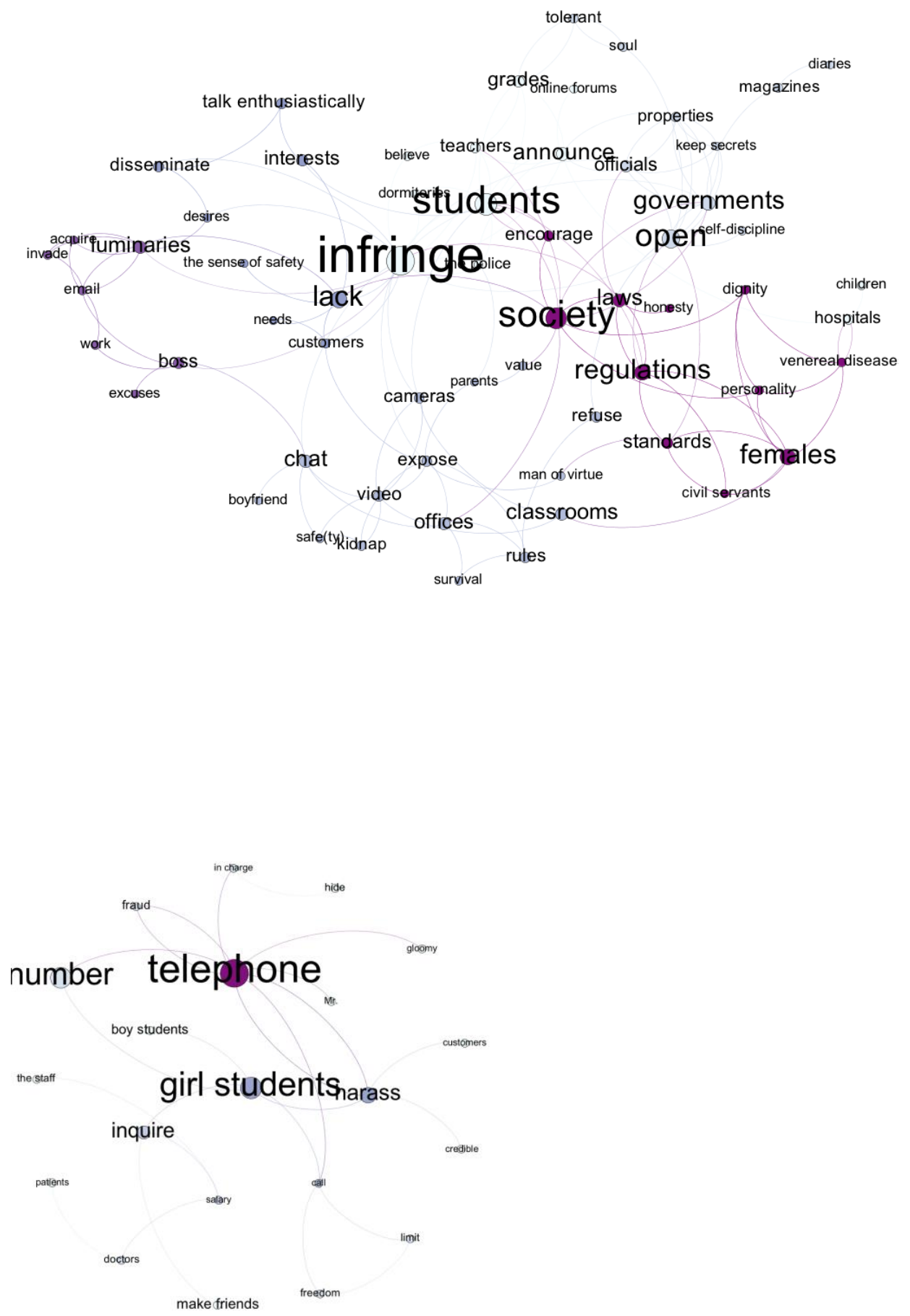
Figure 5

Group 5 the Technological Sphere of Privacy on Sina Weibo

binding

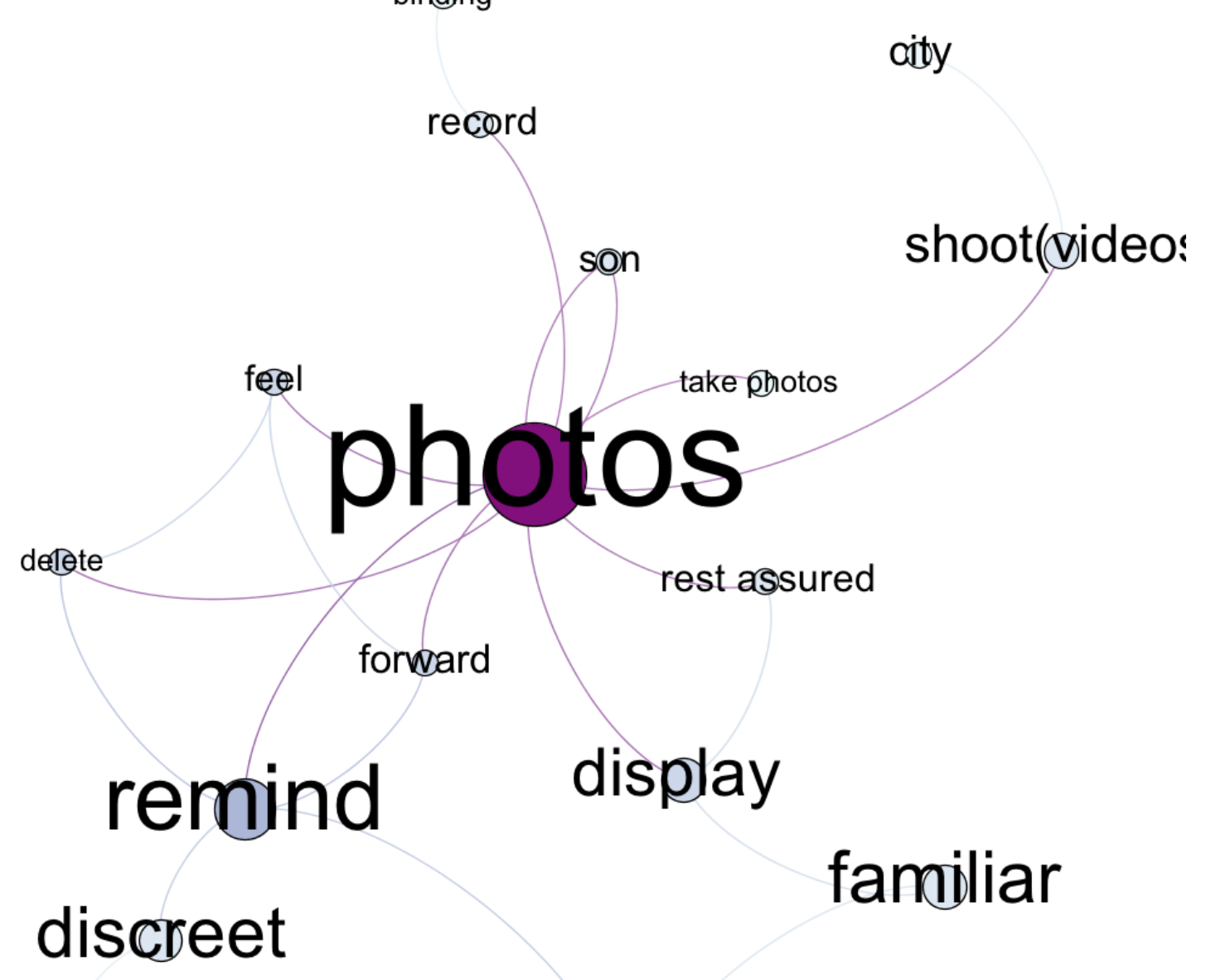

risks

\section{strangers}


Figure 6

Group $6 \& 7$ the Public Policy Sphere of Privacy on Sina Weibo
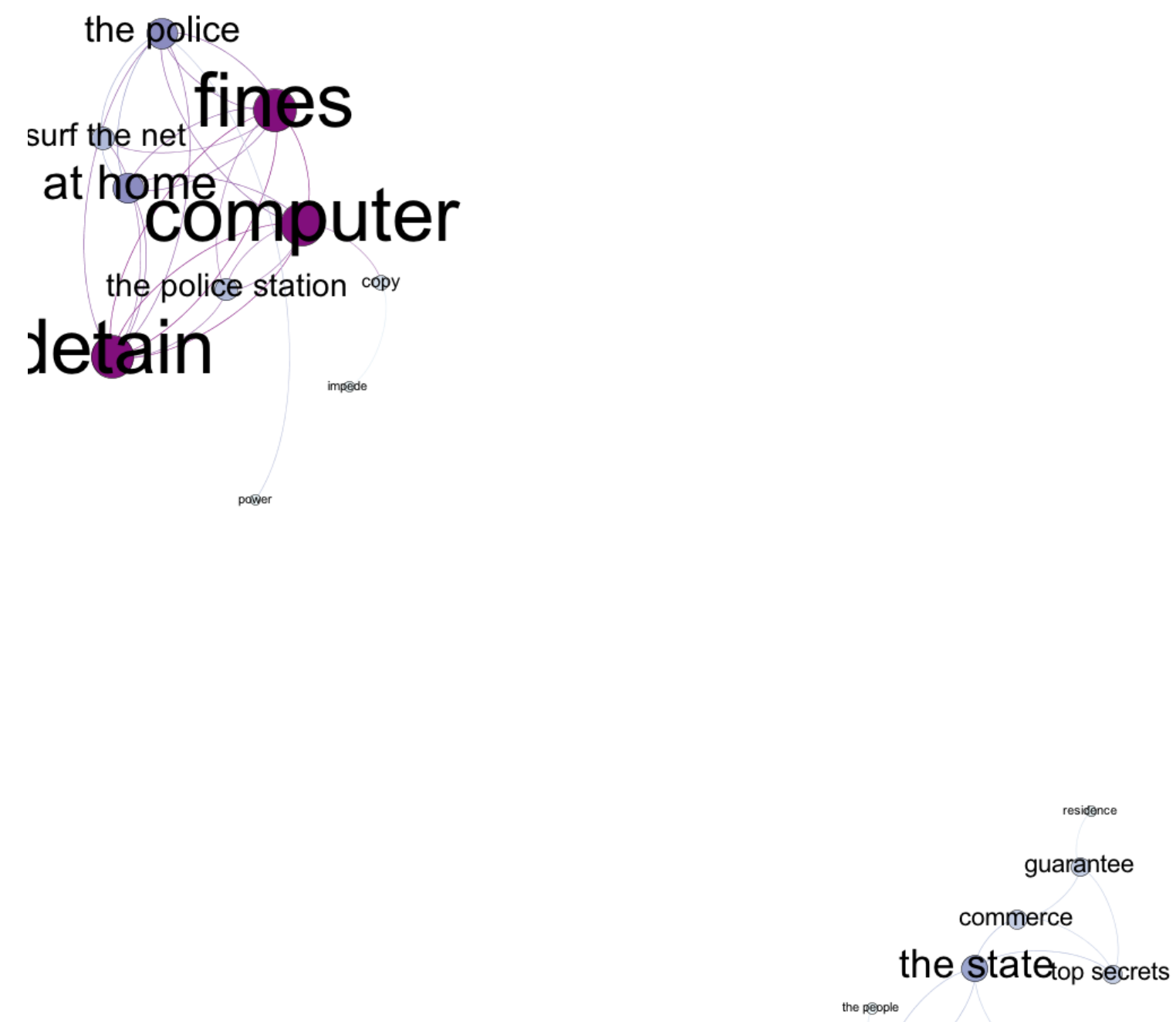

human rights

global 
Figure 7

Group $8 \& 9$ the Social Sphere of Privacy on Sina Weibo

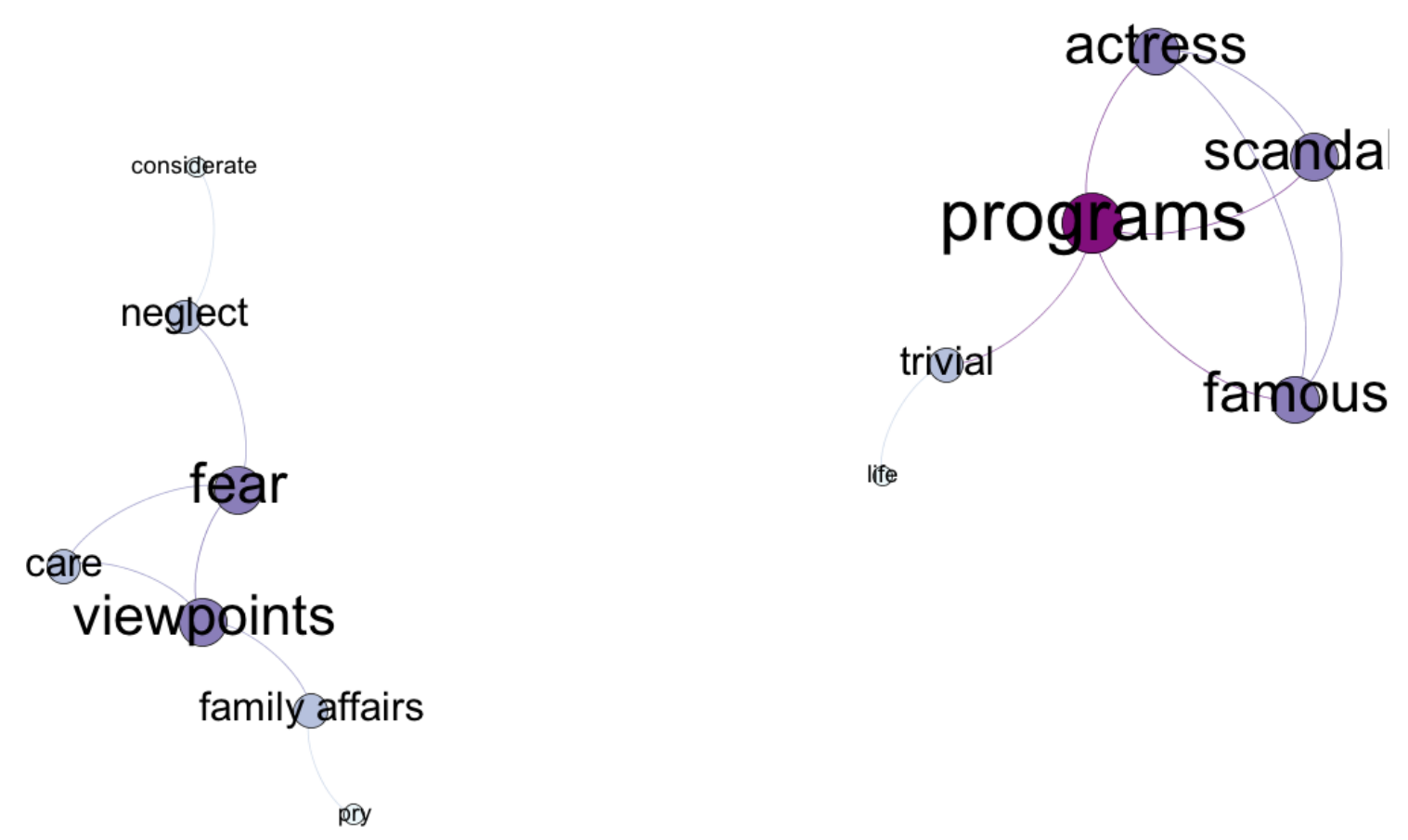

